\title{
The decline of natural sciences in the culture of mass media
}

\author{
Carlos Elías \\ Department of Journalism and Visual Communication, \\ Universidad Carlos III, \\ c/ Madrid 126, 28903 Getafe, Madrid, Spain \\ email: carlos.elias@uc3m.es
}

\begin{abstract}
This study sets out to determine if the interest in and study of natural sciences is declining in western countries as scientists currently contend. Part one demonstrates how survey results reveal a decline of interest in scientific news in the EU. Part two explores the decline of interest further through examining data such as the number of students interested in scientific subjects and scientific careers. I explore the hypothesis that the lack of interest in scientific subjects is influenced by the culture of the mass media, and the manner in which the media covers scientific items. I examine a range of media outlets, from reality TV shows and TV series, to movies and the press. Many aspects of this paper have been discussed in depth in my book published in 2008: La razón estrangulada (Reason Strangled: the Crisis of Science in Contemporary Society).
\end{abstract}

Keywords. communication, science policy, scientific careers, journalism, TV

\section{Introduction}

In 2005 the European Commission published the Eurobarometer "Europeans, Science and technology", a survey among the 25 Member States of the EU†. The data shows that "environmental pollution" is the news theme that gathers the most interest among Europeans, with $8 \%$ indicating that they are very interested and $49 \%$ that they are moderately interested in the topic. "New medical discovery" follows with similar rates (33\% "very interested" and 50\% "moderately interested"). The two news themes with particularly interest to our study, namely "new inventions and technologies" as well as "new scientific discoveries" receive identical scores of 30\% (very Interested) and $48 \%$ (moderately interested).

It is an important point that the news themes that have the lowest rate of interest among the European population are those that are considered as non-scientific, namely "Sports News" (respectively 26\% [very] and 42\% [moderately interested]) and "Politics" (respectively $22 \%$ [very] and $49 \%$ [moderately interested]). From my point of view, these latter results (particularly concerning sport) appear highly surprising, largely because sports always get high TV audience ratings and shares data. Audience viewing ratings constitute direct and indisputable data, while surveys refer to intentions. In this sense, the Eurobarometer points out, it is important to keep in mind that on such a question, respondents may want to answer in a way which is in their eyes socially acceptable. It is therefore possible that many respondents might answer that they are more interested in science than in sports for this reason.

Nevertheless, in order to prove a discernable decline of interest in science and technology themes, the most important evidence is revealed through comparison of the 2005

$\dagger$ see http://ec.europa.eu/public_opinion/archives/ebs/ebs_224_report_en.pdf 
Table 1. Eurobarometer survey. Question: Let us talk about those issues in the news which interest you. For each issue I read out please tell me if you are very interested, moderately interested or not at all interested in it.

\begin{tabular}{lrrrrrrrrr}
\hline Themes & \multicolumn{3}{c}{ Very interested } & \multicolumn{3}{c}{ Moderately interested } & \multicolumn{3}{c}{ Not at all interested } \\
\hline & 2005 & 1992 & Diff & 2005 & 1992 & Diff & 2005 & 1992 & Diff \\
\hline Environmental Pollution & $38 \%$ & $56 \%$ & $-18 \%$ & $49 \%$ & $38 \%$ & $+11 \%$ & $12 \%$ & $6 \%$ & $+6 \%$ \\
New medical discoveries & $33 \%$ & $45 \%$ & $-12 \%$ & $50 \%$ & $44 \%$ & $+6 \%$ & $16 \%$ & $10 \%$ & $+6 \%$ \\
Inventions / technology & $30 \%$ & $35 \%$ & $-5 \%$ & $48 \%$ & $47 \%$ & $+1 \%$ & $21 \%$ & $18 \%$ & $+3 \%$ \\
New scientific discoveries & $30 \%$ & $38 \%$ & $-8 \%$ & $48 \%$ & $45 \%$ & $+3 \%$ & $20 \%$ & $16 \%$ & $+4 \%$ \\
Sports news & $26 \%$ & $29 \%$ & $-3 \%$ & $42 \%$ & $38 \%$ & $+4 \&$ & $32 \%$ & $33 \%$ & $-1 \%$ \\
Politics & $22 \%$ & $28 \%$ & $-6 \%$ & $49 \%$ & $52 \%$ & $-3 \%$ & $29 \%$ & $20 \%$ & $+9 \%$ \\
\hline
\end{tabular}

Eurobarometer results with those of an earlier Eurobarometer (1992, EB 38.1) survey conducted in 1992 among the former 12 Members States of the European Community.

The comparison clearly shows that the proportion of persons "very interested" in the different scientific themes covered has dropped significantly since 1992. The most important decrease concerns interest in environmental pollution ( -18 points). The rate of persons very interested in new medical discoveries also decreased sharply between 1992 and 2005 ( -12 points). For the interest categories inventions and technology and new scientific discoveries, the "very interested" rate dropped by 5 percentage points and 8 points respectively since 1992. Respondents "not at all interested" have increased in all the issues.

Importantly, all those respondents who answered that they are "not at all interested" in either new inventions or technologies or scientific discoveries were then asked to indicate for which reasons they are "not at all interested". The reasons given in the above science categories in the EU-2005 were: I don't understand (32\%); I do not care about it (31\%); I don't need it (16\%); I've never thought about it (12\%); No particular reasons (12\%); I have no time (11\%); I'm too old (2\%); and Other $(2 \%)$.

From this two main reasons emerge to explain the disinterest in science and technology among the Europeans: the lack of understanding and the lack of concern. Indeed, $32 \%$ of respondents point out that they are not interested in science and technology because they do not understand it. A further $31 \%$ indicate that they simply do not care about science and technology. When we look at the socio-demographic characteristics of the respondents, we can distinguish which social groupings are those less likely to be interested in science and technology. Among those who indicated that they don't understand science topics, we find predominantly groupings of persons with the lowest level of education (42\%), persons aged 55 and above and those who are retired (39\%). However, the crucial point is that in those who answered that they don't care about science \& technology topics, the youngest aged people (38\%) and students (37\%) featured strongest. For these social groupings the lack of interest is not due to lack of understanding or education, rather I suggest it is a problem of communication and image.

\section{The decline in science education}

We are reporting a significant decline of interest in the sciences but so far only in accordance with the surveys database. For a more reliable picture, more direct data is required, so here we examine whether a similar trend of decline is seen in the number of students who choose scientific subjects and careers. In 2006 Sussex University announced to shut down its high- ranking chemistry department, the proud source of three Nobel 
laureates. Scientists reacted angrily to the announcement but Sussex University's authorities confirmed the plans to concentrate in other areas, including English, history and media studies.

It was the latest in a long list of closures indicative of the weakening state of chemistry education in the UK universities: King's College London closes chemistry department (2004); University of Wales Swansea stops taking in new chemistry undergraduates (2004); Queen Mary, University of London, merges chemistry with biology (2005); University of Dundee closes division of physical and inorganic chemistry (2005) and University of Exeter merges reduced chemistry department into biological sciences (2005).

According to The Observer (12 March 2006: 12): Financial pressures and the shift of popularity towards less traditional subjects such as media studies have been blamed. In a statement to staff, the vice-chancellor at Sussex University said chemistry was a difficult recruitment area at present times. Unfortunately, this statement is the truth. According to the Higher Education Statistics Agency†, the number of UK students in the first year of full-time and part time degrees courses increased by $11 \%$ between 1995-96 and 200102. Although there was a rise over this period of $53 \%$ in the number of computer science courses, and an increase of $22 \%$ in those studying biological sciences, there were drops of $8 \%$ in engineering and technology and $20 \%$ in the Physical Sciences. In chemistry, numbers fell by $31 \%$ and in physics by $13 \%$.

In contrast, the number of students registered in media studies rose from 6,888 in 1995-96 to 15,905 in 2001-02. So this subject saw a recruitment rise of $43 \%$. Journalism increased by $29.6 \%$. However, the crucial point is that in 2004-2005 the number of students in media studies increased to 26,685. In the academic year 2004-05, the numbers of students registered in UK universities were as follows: 18,520 in chemistry; physics $(14,610)$ and biology $(26,290)$. In media studies there were 26,685 registered, more than in Biology even, making the year 2004-2005 the first year in which there were more students in media studies than in the traditional natural sciences. In journalism also there were 7,570 registered.

UK Secondary School education shows similarly worrying trends. According to figures compiled by Institute of Physicsł, the total number of A-level entries between 1991 and 2003 across all subjects in England, Wales and Northern Ireland increased by $7.4 \%$. Entries in biology rose by $11.0 \%$ over this period, but there were falls of $18.7 \%$ in chemistry, $25.4 \%$ in mathematics, and $29.6 \%$ in physics. The three sciences and mathematics accounted for $30.0 \%$ of all A-level entries in 1993, but only $23.2 \%$ of entries in 2003 .

The British newspaper The Observer (9-July-2006:25) printed an analysis written by Boris Johnson: In the last eight years, 30 per cent of physics departments have closed and chemistry is in similar straits. The universities will say that this is partly to do with the funding formula, which does not cover the extra cost of teaching science, but we all know that the real problem is in the schools. According to Johnson the figures are terrifying. So, in the 20 years from 1985 to 2005, the overall number of entries at A-level rose by 100,000 , from about 680,000 to about 780,000 . Yet maths fell from 71,608 to 58,830 . Physics A-levels slumped from 46,606 to 28,119. Chemistry fell from 40,337 to 38,850 . There are some London boroughs - writes Johnson - where further maths is virtually extinct.

$\dagger$ see the Higher Education Statistics website at http://www.hesa.ac.uk, in statistics on-line, students data, Subject of Study.

$\ddagger$ available at http://www.iop.org in the Physics Education Policy section. 
From the point of view of Sir Alistair MacFarlane, chair of the Royal Society education committee, these downward trends will inflict huge damage on the UK if not reversed, adversely affecting prosperity and the quality of life in the UK.

In Spain there is a similar trend to that in the UK concerning the lack of interest from youth in the study of natural sciences. The Spanish Foundation of Science \& Technology published a survey with the entries in natural sciences from 1988-89 to 2000-01†. The first conclusion is that there was a fall of $6.25 \%$ in numbers of entries in the A-level scientific options. However, the situation is more dramatic in the universities (Elías 2006). In contrast to the UK, in Spain there was a fall of $4.4 \%$ in the total number of university entries, due to the fall in the Spanish birth rate and the lack of overseas students interested in registering in Spanish universities. From 1988-89 to 2000-01 entries in scientific careers fell $1.42 \%$. Maybe this does not sound like much. However, there is a significant fall in the number of those choosing to study classical natural sciences. Data from the Spanish Education Office from 2000-2004 proves physics fell by $12 \%$. Chemistry fell by $18 \%$ (from $30,744$ to 25,171$)$. So that means a fall of 5.570 students in only four years. Mathematics dropped by $20 \%$, and Biology only fell $7.9 \%$.

In contrast to this, and in a similar trend to UK, Journalism has risen $4.4 \%$ but actually the star is Cinema and TV studies, which has risen 13\%. Data from the academic year $2003 / 2004$ shows the following number of students registered: chemistry $(25,171)$; Physics (10,923); Mathematics $(8,266)$; Cinema and TV studies $(11,266)$ and Journalism $(16,656)$. Data from Italy - a country with similar cultural parameters to Spain-shows the following numbers of students registered: in Physics and Maths $(4,126)$; in Chemistry $(2,628)$ and in Media Studies (54,000).

\section{Science and mass media: which relationships?}

Before considering the relationship between science and the mass media it is helpful to know something about the concept of framing. This is related to the agenda-setting tradition, but expands the research by focusing on the essence of the issues at hand rather than on a particular topic. The basis of framing theory is that the media focuses attention on certain events and then places them within a field of meaning. Framing is an important topic since it can have a big influence, including influence upon entire organizations.

Through framing, the media draws the public attention to certain topics, it decides what people should think about, and journalists select the topics. This is the agenda of setting 'thought'. In the news framing is about more than simply bringing up certain topics. The way in which the topics are brought up, the frame in which the news is presented, is also a choice made by journalists. Thus, a frame refers to the way the media and media gatekeepers organize and present the events and issues they cover, and in turn the way audiences interpret what they are provided with. Frames are abstract notions that serve to organise, structure and socially place information. Frames influence the perception of the news by the audience; this form of agenda-setting not only tells people what to think about, but also how to think about it.

In this sense, trends in science coverage from 1945 to 1990 have been identified in a large-scale study by Bauer and colleagues (Bauer et al. 1995). From that study, a single key newspaper, the Daily Telegraph, a national broadsheet, serves us as a salience indicator. Figure 1 gives the changing evaluation tone of science coverage: that is, the degree of positivity or negativity in the representation of science. According to Bauer

$\dagger$ available at http://www.mec.es, Education Statistics section. 


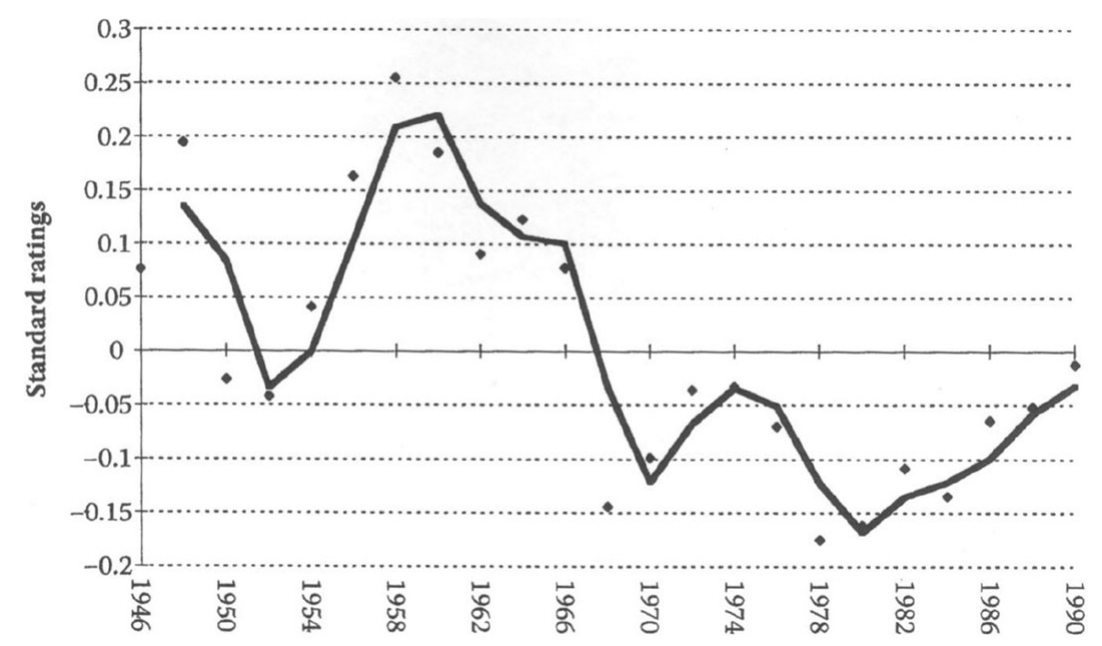

Figure 1. The relative positivity or negativity of science coverage in The Daily Telegraph as a deviation from the long-term average (the zero line). From Bauer et al. (1995).

\& Gregory (2007), the graph shows two clear periods, relative to the long-term average: 1954-1967 is a more positive climate, and 1967-1990 is a more negative climate.

When it comes to the communication of science, not only are scientists and journalists involved, but also fiction films directors and scientific non-fiction film makers. All of them choose a frame, according to their own vision about science. But their choices are often influenced by their university background and if they have worked as a scientist or not. In this sense, different journalists do not hold the same vision about science if they come from a natural sciences background or from a literacy or social sciences background. Scientists and humanists have had a marked tendency to drift apart. It is not that the two groups hate each other, but they share little in the way of common language or interest.

One of the first intellectuals who offered explanation for the big gap between science and humanities was C.P Snow (1905-1980), a British physicist who helped build and then later joined the cold war weapons bureaucracy. Yet he was also a novelist. So he lived in both cultural "worlds", and in 1959 he wrote a very influential book entitled The Two Cultures. Snow observed that our culture was separated into two parts; scientists and everybody else. Indeed this is not new. Since the beginning of the Enlightenment people had tended to be either very literate in science or not literate at all. This ground was famously fought over in the Eighteenth century by the rationalist Voltaire and the romanticist Rousseau. Voltaire had his way in the end, but Rousseaueans have often formed a separate class of technological naysayers. However, the term the two cultures has entered the general lexicon as a shorthand for differences between what might be called the qualitative and quantitative outlooks on life. "The phrase has lived on as a vague popular shorthand for the rift - a matter of incomprehension tinged with hostilitythat has grown up between scientists and literary intellectuals in the modern world" (Kimball 1994).

According to Jon Franklin, a scientific journalist for more than 40 years who won two Pulitzers and also the gold medal from the American Chemical Society, "after World War II the schism was exacerbated by the pace of technological events. By 1960 it was palpable even at academic reception. The rift was definitely there, and it was definitely increasing, and while we may argue about the social seismology involved there is one 
thing that any science writer can tell you for certain. And that the laboratory was on one side of the fault line, and the newsroom the other" (Franklin 1997).

Franklin explained his view of how the perception of science has changed from World War II to the late nineties:

In the late 1970s I was forced to rethink my journalist strategy. I had been reporting and explaining discoveries, but my stories were not being widely read. I generally used the word 'science' early in the story, thinking it would attract readers. The word generally ended up in the headline. But I now realized that the effect was to tell general readers what to avoid. They might trust science in theory, but in practice it had bad personal association. Science pages ghettoized science news, gave people a whole section they could throw away unread. There was something more sinister afoot, as well. As attitudes changed, editors started wanting a certain negative spin on science stories. If you didn't comply you got played inside, or your existence was otherwise made uncomfortable. Some science writers, especially those who identified with the ecology movement, saw hostility to science as a path of success. (Franklin 1997).

On the other hand, according to Franklin, many reporters, decidedly neutral on their topics, found it easy to align themselves with the anti-science faction. This was often couched in terms favouring plurality and an openness toward 'other ways of knowing'.

\section{The decline of the prestige of the scientific: The return of magical thought}

So whenFranklin (1997) writes "many reporters, outspokenly neutral on other topics, found it easy to align themselves with the anti-science faction. This was often couched in terms of favouring plurality, and an openness toward "other ways of knowing", he describes this influence as operating through the mass media of philosophers of science, when they assume science is only other type of knowledge. Because the crucial point is that mass media gatekeepers (journalists, editors, directors, TV broadcaster, filmmaker, etc) usually came from social sciences or humanities backgrounds.

Similars arguments were spread out in public academic arena since October 1987, when two British physicians, T. Theocharis and M. Psimopoulos, published a commentary in Nature against these 'other ways of knowing' and blaming four philosophers of science -Popper, Kuhn, Lakatos and Feyerabend- for introducing into society the idea that there could be another interpretation for reality apart from the scientific one (Theocharis \& Psimopoulos 1987). They suggested that the way of introducing this anti-rational thinking was through journalists and social science students who then decided to work as scientific journalists without knowledge of the natural sciences. In the article entitled "Where science has gone wrong", the two physicians criticized a BBC television broadcast, in the highly regarded Horizon series titled Science... Fiction?†.

They also complained about the The Lister (issue of 20 February 1986), which published an article entitled The Fallacy of Scientific Objectivity. As is evident from their titles, claimed Theocharis and Psimopoulos" these were attacks against objectivity, truth and science".

Articles and programmes attacking the scientific theses and championing the antithesis are published and broadcast regularity by the British media. But oddly, the Royal Society (RS) and the other scientific bodies remain silent and do not deploy their powerful corporate muscle to answer such attacks against science (and sometime against the

$\dagger$ Broadcast on 17 and 22 February 1986. 
RS itself). As a result, it appears, the editors of the popular media have come to the conclusion that RS has not satisfactory answer (Theocharis \& Psimopoulos 1987).

In fact, one of the myths of the twentieth century was that the media controllers were passive vessels through which science popularization passed and that any distortions were mere institutional by-products or even accidents. However, according to Burnham and his influential book How Superstition Won and Science Lost, the truth was otherwise, well beyond the journalists' disposition to sensationalize (Burnham 1987). The first method of distortion was of course to set the agenda. The gatekeepers persistently provided the sensational in lieu of the uplifting, and specifically more superstition than science (Burnham 1987)).

For Burnham the media world is non-naturalistic and superstition is actively competitive with the traditional world of popularized science. At the present time the media world works with the elements of sensationalism and disjointed segmentation of information, and these are exactly the elements of superstition that earlier popularisers of science [in the XIX century and the beginnings of the XX] had attacked with scepticism and naturalism. So completely did the new obscurantism of sensationalism and isolated fact dominate the media world that magical thinking and even conventional superstition are now widely tolerated.

At the International Scientific Conference (Rome, 2002), Umberto Eco talked about The Perception of Science by Public Opinion and the Media. The Italian semiologist stated that, even if we believe ourselves to be living in an Age of Reason mastered by science, we are in fact submitted to the magic mentality that always re-emerges from its ashes and that is supported by the need of the immediate satisfaction of our wishes.

What was magic, what has it been for centuries and what is it still today, even if under a false appearance? The presumption that we can go directly from the cause to an effect by means of a short circuit, without completing the intermediate steps. For example, you stick a pin in the doll of an enemy and get his death; you pronounce a formula and are all of a sudden able to convert iron into gold; you call the angels and send a message through them. Magic ignores the long chain of causes and effects and, especially, does not bother to find out, trial after trial, if there is any relation between cause and effect. (Eco 2002)

According to the German sociologist Max Weber, scientific progress can be described as a process of de-magification that has been going on for millennia in Western culture (). This struggle to eliminate the magic mentality in the explanation of facts has been present throughout history and has become visible in the period of emergence and consolidation of all sciences. Umberto Eco does not agree. He says that in fact middle age magic has been replaced by technology in present days (the magic wand is now the push button: you press and the photo or the photocopy is made, or e-mail is sent, but actually nobody is interested in knowing how the process is working in between. Nobody is interested in the long chain of causes and effects. And this happens because for journalism, and especially for TV, it is impossible to explain this long chain of causes and effects in 60 seconds.

In this sense, Burnham agrees with Eco when observing that at the present time we are coming back to magical thinking where religion and superstition have won and science has lost. And from Burnham's point of view journalists are guilty of that phenomenon. Despite the fact that science and journalism are two of the most important forces of present times, their worlds are so different that they are killing each other: Few newspapermen are interested in a scientific findings unless it can cure cancer while in orbit. This could be called 'rocket-scalped complex'. Likewise few academics are interested in press coverage unless the facts are expressed in mathematical Latin and are heavily qual- 
ified to prove that nothing really important happens. This is of course, the 'scientific dignity-prospective obscurity syndrome' (Burnham 1987).

\section{The rôle of cinema and TV series: the decline of the image of science}

Another question is, if TV and movies rule our society, what is the image that cinema and TV broadcast to society about science and scientists? Since times as early as 1978 scientists at a an annual symposium of the American Association for the Advancement of Science (AAAS) agreed that the popular image of scientists is remarkably bad, and that the mass media must bear a great deal of the responsibility (Maugh 1978). It is very well studied and established that most fiction films depict scientists as the mad archetype: "Without doubt, Dr. Frankenstein is better known today than any other scientists, living or dead", writes George Basalla. Movies and television portray scientists as 'frequently foolish, inept or even villainous' (Basalla 1976).

Scientists often appear as satanists or Faust-like figures in the movies. Even in the movies of the 1930s and 40s there are a number of easily recognizable characteristics. The scientist is usually an elderly white male. He may be insane or evil. But since the 1950s, the cackling madman hatching plots to rule the world has more or less vanished from the screen. In films of last 50 years, the scientist is not always a white male, but often is well-meaning yet obsessed with the pursuit of knowledge. Amoral rather than immoral, he will stop at nothing to find out what he wants to know. He will not let human sensitivities or sympathies stand in this way. He displays his insensitivity in small ways. If the scientist has family, he usually neglects them. More often, scientists in the movies are shown to be bachelors or widowers. They are rarely shown as being sexually or emotionally involved. The audience may hear the scientist's beautiful daughter or assistant say that he is married to his test tubes.

However, the scientist's capacity for destruction on a large scale is the major recurring theme in the films. As Sontag (1977) notes, "science fiction films are not about science. They are about disaster, which is one of the oldest subjects of art. In science fiction films disaster is always extensive". However, the scientist's capacity for causing disaster has increased since the 30 s to present time. In the horror film of the 30 s the worst a scientist could do was lay a small Bavarian village to waste. But more lately they have the power to imperil the world (The Core, by J. Amiel, 2003), or even many worlds.

Note that the scientist most often wreaks havoc by building or creating something. The process of scientific research is rarely distinguished from the process of technological application. In cinema they are usually one and the same. B-films of the 1950s reflected the fears of that time - nuclear war, dehumanisation and political subversion - in the same ways that films of the 90 s and 2000s reflect the fear of genetic manipulation. The point is that the one responsible for the process of dehumanization is the scientist.

Of course, scientists were often seen as responsible for the sudden appearance of monsters. In the fifties prehistoric monsters were awakened through nuclear testing. In the nineties and present times monsters are resurrected through genetic manipulation, as in for example Jurassic Park and The Lost World. Scientists have also played an important rôle in the many alien invasions and infiltrations portrayed in films. The aliens, cold and implacably hostile, either bring ruin to the world with flying saucers and ray guns, or take over the minds of humans by remote-control. Despite this, the foolish scientist always wants to communicate with the hostile invader, while the military men wisely see the menace and try to destroy the creature. This association between scientists and 'non human behaviour' is easy to find in the culture of mass media. One of the better 
examples is Star Trek, where Leonard Nimoy played the Enterprise's "Science Officer", one Mr. Spock from the planet Vulcan. The inhabitants of Vulcan had no emotions, and for much of the series, Mr. Spock was a relentlessly rational, typically heartless scientist. Differences in image are obviously stacked in favour of magicians over scientists in the movies or on TV. Wizards such as Harry Potter (not only in the book but also in the movies) or witches such as the Halliwell sisters in the supernatural one-hour drama from Spelling Television, Charmed, give an image of "good people concerned with saving the world". If we visit the web site of the Charmed show (http://ww.tv.com/charmed) we read:

"Charmed chronicles the conflicts and the love among three vastly different sisters and their need to come together to fulfill an ancient witchcraft prophecy. The Halliwell sisters were always different, not just from the world around them, but also from each other. Though bound together by blood and destiny, these twentysomething women could not have been more dissimilar. Yet the discovery that the three sisters were powerful good witches, foretold as the Charmed Ones, created a bond that reached far beyond petty sisterly grudges, and they banded together to keep their otherworldly witchcraft a secret and vanquish all comers. After seven years of protecting the innocent, demon fighting and generally ridding the world of evil, the Halliwell sisters have begun a search for a different destiny - living normal lives free of fighting demons. At the end of last season, the sisters appeared to sacrifice themselves to rid the world of the evil Zankou."

However, this is the key question: Are the images (of mad scientists and good magicians) eroding public support for science, and turning away potential Einsteins, Paulings and Pasteurs before they mature enough to appreciate the joy and the wonders of science? According to Basalla there is a feedback loop between widely held public ideas of science and their popular representation. He argues that by presenting these attitudes in a popular medium [...] the creator of popular culture perpetuates and strengthens them.

Analysis of the National Science Board's Science and Engineering Indicators Survey provides evidences that different media -newspapers, general television, science television and science magazines- do affect perceptions differently. In a study published by Nisbet et al. (2002), the authors conclude that "the negative images of science on television appear to also promote a competing schema related to the promise of science. Their results also indicate an education gap in media use, knowledge of science and perception of science. So individuals with higher levels of general education are more likely to read newspapers containing a better image of science, and use scientific media, and are less likely to engage in general television viewing. So society's best educated are less likely to hold reservations about science and are more likely to believe in the promise of science.

"Even though these demographic characteristics are important in understanding the public perception of science, our results demonstrate that above and beyond these demographic influences, the media does matter. In our study we confirm the fears of scientists that some forms of media content could be doing damage to the public perception of science. (Nisbet et al. 2002)

Their results demonstrate that, particularly in the case of television, there is a positive relationship between general television viewing and reservations about science. In this regard, the television series The $X$-Files provides an interesting case study, featuring a Holmes and Watson duo of FBI detectives. In the series, Fox Mulder is a credulous parapsychologist, and Dana Scully is a sceptical medical doctor with a background in physics. Mulder and Scully's cases, d erived from filing cabinet collections of leads designated "X" for "unexplained", take them to the border of reality. From psychic phenomena to genetic mutation to alien abduction, examples of the paranormal reveal themselves in each episode. Very often the parapsychological explanation wins over the scientific one. The 
$X$-Files has been characterised by prominent scientists and other critics as the latest example of entertainment television's continual depiction of science as failing and incapable of offering satisfactory scientific explanations for extraordinary occurrences. It also illustrates the way rational and scientific efforts are increasingly depicted as subordinate to mystical speculation (Dawkins 1998).

\section{The decline in the economical conditions and the media}

Senior scientists may recognise that they and their students should take more time for their personal lives, but they adapt to their incentives. Scientists work hard, but ... does it mean that at least scientists earn a lot of money? No. PIs interviewed by Freeman et al. (2001) recognise that graduate students and postdocs often struggle economically. But as long as cheap postdoc or graduate student labour is available, PIs will use them as their primary labour input. For this reason senior scientists are so worried about the decline in scientific careers. If encouraging graduate students and postdocs to narrowly specialize helps PIs win the research tournament, this will occur even if alternative forms of training, or leaving the lab sooner, might better serve the students and postdocs (Freeman et al. 2001). In the same vein, if PIs cannot attract postdoctoral fellows from the United States or institutions cannot attract qualified graduate students, they widen their search geographically or lower admission standards.

Other problem is that the long duration of graduate and postgraduate training and low rate of pay gives scientists lower lifetime income than people in other careers that require high levels of education. According to Freeman many scientists do not obtain their first salary until their mid-30s. This is new, as this was not the case in the $60 \mathrm{~s}, 70 \mathrm{~s}$ or 80 s. So from my point of view, this tournament structure that generates good research by employing idealistic young graduate students and postdoctoral fellows at low cost is further evidence of the decline of science.

The worrisome reality is that scientists and engineers aren't well paid, considering their skills -and, specially for PhDs- the time required to gain a degree. This means the job market is too weak to attract increasing numbers of students in western countries. As Samuelson (2005) reported, from 1990 to 2000, average income for engineering PhDs increased from USD 65,000 to USD 91,000, up 41 percent; PhDs in natural sciences (physics, chemistry) rose from USD 56,000 to USD 73,000, up 30 percent. Meanwhile, average doctors' incomes increased from USD 99,000 to USD 156,000, up 58 percent; and lawyers went from USD 77,000 to USD 115,000, up 49 percent.

The true situation may be worse. Next to other élites, scientific and engineering PhDs fare poorly. According to Samuelson the $891 \mathrm{MBA}$ recipients of the Harvard Business School's class of 2005, at an average age of 27, earn a median starting salary of USB 100,000 .

These dramatic economic conditions for scientists are other sign of decline. Clever young people love money and free time as well as being interested in a good profession. This could explain some data, for example why in 1975, the United States produced more science graduates and more engineering and scientific PhDs than Europe and more than three times as many as in all of Asia. According to the National Science Foundation, in 2001 China graduated 220,000 engineers, compared to about 60,000 for the United States. All the data mentioned above very often appears in the mass media. In contrast, a study concluding that the proportion of Britain's top journalists who were privately educated has risen to 54 of the current top 100, up from 49 twenty years ago, has had very little media coverage. One of the reasons for this trend, according to Howard Davies (2006), director of London School of Economics, may be the recruitment pattern of 
media organisations. Increasingly, writes Davies, they expect graduates to take unpaid internships if they wish to get their feet on the first rung of the ladder. That skews their recruitment towards the scions of better-off families, who can afford to work for nothing for a while (Davies 2006). So that means journalists' working conditions are even worse than scientific ones, because scientists can get badly paid but journalists are not paid at all. This is yet further indication that many people choose media studies because of glamour incentive and not because of mass media working expectations. Nevertheless the working conditions of journalists barely appears in the mass media because its own credibility could be threatened.

\section{Conclusion}

When Samuelson reports in The Washington Post about scientists' low salaries compared with other professionals, or when The Observer writes about why academic authorities are going to shut down the Chemistry Department at Sussex University or publishes a report about a strike of young scientists complaining about their working conditions, the idea we are spreading among the public is that Science is something in decline. And of course, nobody wants to enrol in a field that is in decline. Everybody prefers to enter a field enjoying success. If we add to this the impression given by the mass media that science is not the truth but just another way of knowledge, and the archetype of the mad scientist so often broadcast on TV series and in movies, we have a group of factors that could explain why so many people are not interested in reading about science, or study a scientific career and the worst thing: why so many people don't care about science. If the responsibility lies with the mass media or within present day social values, this is something I cannot fully explain here. But, from my point of view, the truth is that we have a real problem if people prefer (or place at the same level of importance) a scientific explanation and a magical superstition. We have a real problem if clever students prefer an MBA to studying biosciences.

Nevertheless universities have their own responsibilities for this phenomenon of the decline of natural sciences. Young students are fascinated by media studies instead of scientific ones because media studies are glamorous and funny. I agree. But another explanation for the rise of interest in media studies is the fact that they are easier to pass than scientific (or even literacy) subjects. From my own experience -I hold degrees in both chemistry and journalism- I spent about 23 times more hours to pass my degree in chemistry than my degree in journalism. And of course I remember particularly enjoying my cinema and TV classes. They were amusing, in contrast to the boring, and hard, classes on quantum physics or mathematics. So if both subjects - chemistry and journalism- are university degrees with the same level of prestige and social recognition, why should a clever teenager be interested in wasting 23 times more effort in studying something such as physics and chemistry without sufficient worth for that subject in the present mass media culture.

Why, some teenagers could ask, study something hard and boring instead of something funny, enjoyable, glamorous, and with the potential to become famous? From my point of view, the answer is because if you study naturals sciences, you obtain a greater capacity to understand the world, even the mass media world. However this is very difficult to explain to young students (even to people from literature or social science studies). Only if you study both degrees are you aware of the importance of learning natural sciences to become a journalist, a politician or whatever you want.

In fact, in 2006, Javier Moreno, a former chemist, was appointed editor in chief of the main Spanish newspaper, El Pais. The newspaper's owner, Jesus de Polanco, consid- 
ered Moreno the best qualified person to rule the newspaper 'in this complicated period for the mass media'. Furthermore, the most important Spanish film producer, Agustín Almodovar, who has produced, among others, all the movies of the best Spanish film director, Pedro Almodovar, is a former chemist as well. Some years ago, in Spain and in the UK, journalism and media studies used to be taught at 'Polytechnic universities' [in Spanish: Escuelas universitarias or institutos profesionales] which were considered to have lower academic standards than traditional universities which used to give degrees such as physics, chemistry, law, economics or philosophy. But at present time, despite some prestigious universities such as Oxford or Cambridge refusing to create media studies degrees, the majority of them are very interested of doing so as a way of recruiting a lot of students fascinated by mass media culture. The crucial point is that according to a report by Peter Lampl (Sutton Trust) "the Oxbridge university level continues to dominate the proportion of Britain's top journalists (Davies 2006). That means that journalism needs people with other types of interests and skills than those they learn in media studies. Even so, five years ago, British editors affirmed that they potentially accepted anybody to work as a journalist, except those with a degree in media studies. Despite this reality, British and Spanish universities prefer to close scientific departments and open mass media ones. In conclusion, we have a real problem if scientists, universities authorities, journalists and filmmakers don't speak to each another about this worrying situation.

\section{References}

Basalla, G. 1976, in Science and its public: the changing relationship, G. Holton \& W. A. Blanpied (eds.) (Kluwer: Reidel Publishing), p. 261

Bauer, M. W., Duran, J., Ragnarsdottir, A., \& Rudolfdottir, A. 1995, Science and Technology in the British Press, 1946-1990, Technological Reports (London: Science Museum)

Bauer, M. W. \& Gregory, J. 2007, in Journalism, Science and Society, M. W. Bauer \& M. Bucchi (eds) (New York: Routledge), p. 33

Burnham, J. C. 1987, How Superstition Won and Science Lost. Popularizing Science and Health in the United States (New Brinswick: Rutgers University Press)

Davies, H. 2006, The Independent (13 July 2006)

Dawkins, R. 1998, Skeptical Inquirer, 22, 28

Eco, U. 2002, Il mago e lo scienziato, La Reppublica (10 November 2002) †

Elías, C. 2006, Estudios sobre el mensaje periodístico, 12, 253

Elías, C. 2008, La razón estrangulada (Barcelona: Debate)

Franklin, J. 1997, The end of Science Writing. The Alfred and Julia Hill Lecture. University of Tennesseeł.

Freeman, R., Weinstein, E., Marincola, E., Rosenbaum, J., \& Solomon, F. 2001, Science, 294, 2293

Kimball, R. 1994, The New Criterion, 12, 6

Maugh, T.H. 1978, Science, 200, 37

Nisbet, M.C., Scheufele, D.A., Shanahan, J., Moy, P., Brossard, D., \& Lewenstein, B.V. 2002, Communication Research, 29, 584

Samuelson, R.J. 2005, The Washington Post (10 August 2005)

Sontag, S. 1977, in A wake in the dark: an anthology of American film criticism, 1915 to the present, D. Denby (ed.) (New York: Vintage Books), p. 263

Theocharis, T. \& Psimopoulos, M. 1987, Nature, 329, 595

Weber, M. 1959, Politik als Beruf / Wissenschaft als Beruf (Berlin: Duncker \& Humblot)

$\dagger$ http://ricerca.repubblica.it/repubblica/archivio/repubblica/2002/11/10/ilmago-lo-scienziato.html

$\ddagger$ available at http://jonfranklin.com/Teaching/End_of_Science_Writing.html 